\title{
ISLAM, PEREMPUAN DAN PENDIDIKAN
}

\author{
Mujiburrahman
}

Mujib71@hotmail.com

\begin{abstract}
The article will discuss various viewpoints on the issues affecting women in Islam, and how they influence the views regarding women education. Their views generally can be divided into conservative, progressive and philosophical. All these views, in general, regard that like men, women are obliged to search for knowledge. In Indonesia, since the $19^{\text {th }}$ century, women have already been involved in learning religion. However, for some cultural reasons, in this period, the access for women to modern education was still limited. On the other hand, from the $20^{\text {th }}$ century up to now, like male Muslims, Indonesian female Muslim have more opportunies in education. Moreover, the symbolic-philosophy of complementary relations between male and female can also become an alternative to conservative or liberal philosophy of education.
\end{abstract}

Keywords:perempuan, pendidikan, Islam

\begin{abstract}
Abstrak:Artikel ini akan membahas berbagai sudut pandang pada isu-isu yang mempengaruhi wanita dalam Islam, dan bagaimana mereka mempengaruhi pandangan mengenai pendidikan perempuan. Pandangan mereka umumnya dapat dibagi menjadi konservatif, progresif dan filosofis.Semua pandangan ini, secara umum, hal itu seperti laki-laki, perempuan diwajibkan untuk mencari pengetahuan. Di Indonesia, sejak abad ke-19, perempuan telah terlibat dalam agama belajar. Namun, untuk beberapa alasan budaya, dalam periode ini, akses bagi perempuan untuk pendidikan modern masih terbatas. Di sisi lain, dari abad ke-20 sampai sekarang, seperti Muslim laki-laki, perempuan Muslim Indonesia memiliki opportunies lebih dalam pendidikan. Selain itu, simbolikfilosofi hubungan saling melengkapi antara pria dan wanita juga bisa menjadi alternatiffilsafat konservatifatau liberal pendidikan.
\end{abstract}

Kata Kunci:perempuan, pendidikan, Islam

\section{PENDAHULUAN}

Masalah perempuan sepertinya tak pernah kering untuk dibahas, meskipun sudah banyak sekali penelitian yang dikerjakan, buku yang diterbitkan dan artikel-artikel yang ditulis.Pusat-pusat kajian perempuan, kajian wanita atau kajian jender, bertumbuhan bagai jamur di musim hujan di berbagai tempat, baik sebagai lembaga pemerintah ataupun swasta.Di jajaran pemerintahan kita sekarang, ada
Departemen Pemberdayaan Perempuan. Di zaman Orde Baru, ada juga yang disebut Menteri Urusan Peranan Wanita. Selain itu, di zaman Reformasi adapula Komnas Perempuan.

Masalah perempuan semakin menarik untuk dibicarakan, kadang dengan emosi yang berapi-api, manakala berhubungan dengan agama, tidak terkecuali Islam.Para sarjana, ulama dan cendekiawan Muslim, hampir di seluruh penjuru dunia, 
banyak yang terpanggil untuk ikut serta memecahkan beragam persoalan yang dihadapi perempuan Muslim. Seperti lazimnya dalam dunia pemikiran, para pemikir itu akhirnya sampai pada kesimpulanyang bermacam-macam, bahkan bertentangan satu samalain. Merekajuga menggunakan pendekatan yang berlainan dalam menafsirkan sumber-sumber otoritatif dalam Islam seperti Alqur'an, Hadis dan pendapatpendapat para ulama terdahulu.

Secara umum aneka wacana tentang Islam dan perempuan tidak bisa terlepas dari konteks sejarah, sosial dan budaya di mana Islam itu dianut.Tradisi Islam yang tertuang dalam sumbersumber otoritatif tetap menjadi rujukan utama para pemikir Muslim.Namun dalam menafsirkan sumber-sumber itu, mereka ada yang cenderung konservatif, progresif atau filosofissimbolis. Demikian pula halnya kalau kita lihat secara khusus masalah perempuan di bidang pendidikan. Dalam hal ini, perbedaan pandangan juga kita temukan, meskipun mereka sepakat bahwa laki-laki dan perempuan sama-sama wajib menuntut ilmu.

\section{Konteks Sosial dan Budaya}

Dorongan yang kuat untuk memikirkanmasalah-masalah perempuan itu terutama berasal dari tantangan dan peluang yang dihadirkan oleh modernisasi, yang pada dasarnya berasal dari Barat.Modernisasi yang berjalan di berbagai penjuru dunia tidak hanya sekadar berarti pemanfaatan sains dan teknologi bagi kemudahan dan kenyamanan hidup manusia, tetapi juga membawa serta nilai-nilai tertentu seiring dengan perubahan sosial, budaya dan politik yang berlangsung di masyarakat. Nilai-nilai seperti persamaan, kebebasan dan persaudaraan, yang kemudian dirumuskan secara lebih rinci sebagai Hak-Hak Asasi Manusia (HAM), mau tidak mau menantang doktrin-doktrin agama yang sudah mapan, termasuk yang berkenaan dengan perempuan. ${ }^{1}$

Bagi kaum Muslim, kemodernan yang erat hubungannya dengan sejarah kebudayaan Barat, tidak mudah untuk disikapi, terutama karena alasan-alasan kesejarahan dan kejiwaan. Sejarah panjang konflik bersenjata dalam Perang Salib antara kaum Muslim Timur Tengah dan Kristen Eropa masih kuat tertanam dalam ingatan.Sementara itu, banyak sekali kaum Muslim yang mengalami penjajahan bangsa Eropa yang tentu saja menyisakan bekas-bekas traumatik yang masih kuat.Dalam banyak kasus, perjumpaan kaum Muslim dengan gagasan-gagasan mengenai hak-hak perempuan justru terjadi pada saat penjajahan berlangsung. Dengan kata lain, sebagian kaum Muslim menemukan ide-ide tentang nilai-nilai kesetaraan justru dari orang-orang Eropa yang menjajah itu.

Selain pengalaman yang relatif sama dalam perjumpaan dengan 
kebudayaan Eropa, kaum Muslim di berbagai wilayah di dunia tentu memiliki latar belakang budaya yang berbeda-beda pula. Kebudayaan Saudi Arabia, Mesir, Iran, Malaysia, Indonesia, Maroko, Turki dan sebagainya tentu berbeda dan beragam.Di Indonesia saja, terdapat 360 etnis yang berbicara dengan 716 bahasa yang berbeda.Sebagian mereka memakan makanan yang berbeda, menikmati musik yang berbeda, dan bahkan menyembah tuhan yang berbeda. ${ }^{2}$ Maka tak mengherankan pula, posisi perempuan di masyarakat dengan latar belakang budaya tertentu tidak jarang berlainan dengan perempuan lain yang berlatar belakang budaya yang berbeda. Belum lagi kalau kita mengaitkannya dengan kelas sosial dan status seseorang.Apa perbedaan perempuan Muslim kelas menengah dan kelas atas dengan yang dari kelas bawah? Apa pula perbedaan antara perempuan yang terpelajar dengan yang tidak terpelajar? Apa perbedaan antara anak perempuan kiyai dan anak perempuan yang berasal dari kalangan awam agama? Bagaimanapula dengan perempuan bangsawan?

\section{Ragam Penafsiran Agama}

Kompleksitas masalah perempuan dan Islam ditambah lagi dengan banyaknya persoalan yang terkait dengan ajaran-ajaran agama yang ada.Yang paling banyak dibicarakan biasanya adalah seputar hukum Islam, atau tepatnya, fiqh. ${ }^{3}$ Masalah yang dibahas mulai dari perbedaan aturan-aturan formal dalam ritual untuk perempuan dibanding laki-laki, sampai persoalan syarat-syarat perkawinan, waris, kesaksian, poligami, mut'ah, hubungan seksual, hak reproduksi, bepergian dengan atau tanpa muhrim, menjadi pemimpin dalam ibadah dan politik, berpakaian, menyanyi di depan lakilaki, hingga boleh tidaknya perempuan menyetir mobil di jalan raya.

Tentu saja, beragam masalah tersebut berpangkal dari penafsiran para ulama terhadap teks-teks Alqur'an dan Hadis.Biasanya ketegangan terjadi manakala suatu ketetapan dalam hukum fiqh menunjukkan suatu kecenderungan yang dianggap diskriminatif terhadap perempuan, atau tepatnya menguntungkan laki-laki dan merugikan perempuan karena tiadanya perlakuan yang setara dan adil.Dalam menghadapi masalah ini, kaum Muslim akhirnya berbeda pendapat. Ada yang tetap ingin bertahan dengan yang sudah ada, antara lain sebagai upaya peneguhan identitas keislaman di tengah-tengah modernisasi. Di sisi lain ada pula yang berusaha beradaptasi dengan mengembangkan penafsiran baru sehingga kesetaraan dapat diterima tanpa membuang kepercayaan pada teks-teks agama. Akhirnya, adapula yang menggali tradisi Islam di luar fiqh seperti filsafat dan tasawuf 
guna menemukan perspektif lain.

Kita ambil contoh soal hak waris perempuan yang disebutkan dalam Alqur'an sebagai setengah dari bagian laki-laki. ${ }^{4}$ Menurut pandangan konservatif, karena pernyataan Alqur'an sudah dengan jelas dan tegas dalam masalah ini, maka tak ada pilihan lain kecuali menerimanya. Sisi keadilan dari ketetapan ini dipahami terkait dengan ajaran Islam bahwa laki-laki adalah orang yang berkewajiban memberi nafkah pada isteri dan anakanaknya, sedangkan perempuan tidak.Sementara penafsiran progresif mengatakan, pembagian itu dapat saja diubah meskipun Alqur'an sudah nyata menyebutkan perempuan hanya dapat setengah bagian laki-laki.Alasannya, semangat dasar hukum Islam adalah keadilan. Jika pertimbangan rasa keadilan menuntut agar perempuan dapat sama dengan laki-laki atau bahkan lebih besar, maka bisa saja dilakukan. Hak perempuan setengah laki-laki dalam al-Qur'an harus dilihat dalam konteks masyarakat Arab ketika itu di mana perempuan bukannya mendapatkan hak waris, tapi justru menjadi harta waris.Selain itu, sistem kesukuan yang berbasis laki-laki (partiarki) mengharuskan perempuan ikut suku suaminya. Maka harta milik perempuan akan menjadi harta suaminya. Dalam kondisi demikian, menyamakan bagian laki-laki dan perempuan bisa menimbulkan perang antar suku.Adapun kondisi kita sekarang sudah berlainan. Maka kadar pembagian dapat disesuaikan dengan pertimbangan kemaslahatan.

Terlepas dari kontroversi penafsiran di atas, dalam praktik di lapangan, kebanyakan masyarakat cenderung untuk berdamai di antara sesama ahli waris. Adapula yang mengambil langkah lain, misalnya sebelum meninggal dunia, orangtua menghibahkan sebagian hartanya kepada anak perempuannya terlebih dahulu. Ada pula ulama yang menganjurkan agar harta yang ditinggalkan, sebelum dibagi, terlebih dahulu dibagi dua.Separuhnya untuk isteri atau suami yang ditinggalkan, sedangkan separuhnya lagi baru dibagi berdasarkan hukum waris Islam.Inilah yang dikenal dengan harta papantangan dalam budaya Banjar, atau harta gonogini dalam budaya Jawa. ${ }^{5}$

Lalu bagaimana pandangan filosofis-simbolik?Pandangan ini memang tidak menyentuh langsung hal-hal praktis seperti hukum fiqh di atas. ${ }^{6}$ Laki-laki dan perempuan dilihat secara lebih dalam dan menyeluruh, terkait dengan hakikat alam semesta (kosmos), wujud manusia dan struktur keberadaannya. Laki-laki (maskulin) dan perempuan (feminin) tidak dipahami sebagai ciri seksual semata, melainkan sebagai sifat-sifat khas yang tampak sepintas kontradiktif atau kompetitif, tetapi pada hakikatnya 
bersifat saling melengkapi (komplementer). Tuhan sang Pencipta memiliki sifat-sifat agung (jalâl) seperti Perkasa, Kuasa, Menghukum dan Memaksa, dan memiliki sifat-sifat indah (jamâl) seperti Pengasih, Pemelihara, dan Pengampun. Dua jenis sifat ini juga ditemukan pada alam semesta dan manusia. Langit adalah maskulin sebagai pemberi hujan dan cahaya, dan bumi adalah feminin yang menerima dan tempat bersemainya benih. Demikian pula pria dan wanita, keduanya saling melengkapi dan membutuhkan sehingga kehidupan ini dapat berjalan seimbang.Dalam perspektif ini, sifat-sifat maskulin seperti menguasai dan mengeksploitasi di satu pihak, dan sifat-sifat feminin seperti menyayangi dan mengasuh di pihak lain, keduanya ada pada diri manusia, laki-laki dan perempuan.

\section{Perempuan dan Pendidikan}

Terlepas dari perbedaan perspektif di atas, barangkali tidak berlebihan kalau kita mengatakan semua pemikir Muslim sepakat bahwa menuntut ilmu itu wajib bagi laki-laki dan perempuan, sebagaimana yang disabdakan oleh Nabi Muhammad SAW.Apalagi ayat pertama yang diwahyukan kepada Rasulullah SAW adalah perintah membaca, iqra'. Sejumlah hadis sahihjuga menyebutkan bahwa Nabi saw memberikan pelajaran agama kepada kaum perempuan dalam majelis yang khusus untuk mereka.

Namun harus diakui pula, dalam tradisi pemikiran Islam klasik di bidang fiqh, sangat sulit bagi kita menemukan contoh adanya seorang ahli fiqh perempuan.Filosof Muslim perempuan, setahu saya, juga tidak ada. Yang kadang kita temukan adalah tokohtokoh sufi perempuan seperti Rabi'ah al'Adawiyah dan beberapa guru sufi perempuan yang kepada mereka sufi terkenal Ibnu al-'Arabi berguru.

Kalau kita merujuk kepada tokoh terkenal, Kartini (1879-1903), maka kita menemukan satu kasus perempuan Indonesia yang tidak mendapatkan kesempatan mendapatkan pendidikan yang setara dengan laki-laki dalam menuntut ilmu-ilmu modern. ${ }^{7}$ Berbeda dengan kenyataan ini, dalam tradisi lisan masyarakat Banjar diketahui bahwa Kitab Parukunan Jamaluddin yang sampai sekarang masih beredar di masyarakat, sebenarnya adalah karya seorang perempuan bernama Fathimah. ${ }^{8}$ Dia adalah puteri dari pasangan Syarifah dengan Abdul Wahab Bugis.Syarifah adalah anak Syekh Muhammad Arsyad al-Banjari, dan Fathimah berarti cucu beliau.Keberadaan Fathimah sebagai penulis kitab Parukunan menunjukkan bahwa sejak abad ke-19, penguasaan ilmu-ilmu agama tidak hanya terbatas di kalangan laki-laki, tetapi juga perempuan di masyarakat Banjar. Tetapi mungkin karena dalam 
pandangan masyarakat waktu itu, perempuan tidak perlu tampil ke depan sebagai tokoh agama, maka nama penulis yang dicantumkan dalam edisi cetak kitab tersebut adalah Mufti Jamaluddin, paman dari Fathimah. Yang menarik, kitab ini tidak menyinggung sisi-sisi fiqh klasik yang kini dianggap diskriminatif terhadap perempuan.Penulisnya bahkan tidak menyebut mandi usai haid sebagai bersuci (yang secara implisit menganggap haid adalah kotor), tetapi hanya menyebutnya sebagai mandi wajib. Selebihnya, kita tidak mengetahui secara rinci peran apa yang dilakukan Fathimah sebagai ahli agama di masyarakat, terutama karena ketiadaan sumber-sumber historis.

Namun tak salah kiranya dikatakan bahwa di Indonesia secara umum perempuan memiliki kesempatan yang relatif sama dengan laki-laki untuk menuntut ilmu agama. Menurut pengamatan Abdurrahman Wahid, sejak sangat dini pendidikan pesantren di Jawa sudah membuka pendidikan untuk kaum perempuan. ${ }^{9}$

Saya tidak mengetahui secara persis kapan pesantren putri mulai dibuka di Kalimantan Selatan.Yang jelas, pesantren-pesantren tua di daerah ini, seperti Rasyidiyah Khalidiyah di Amuntai, Ibnu al-Amin di Barabai dan Darussalam di Martapura, semua memiliki pendidikan khusus puteri. Apalagi kalau kita mengamati pesantren-pesantren yang lebih muda usianya. Di tingkat pendidikan tinggi, terutama sejak tahun 1960-an, sejumlah IAIN sudah dibuka di berbagai wilayah di Indonesia, yang memberikan kesempatan yang sama bagi laki-laki dan perempuan untuk mendalami ilmuilmu agama. Maka guru agama dan bahkan hakim agama di negeri ini, tidak sedikit yang perempuan.

Dari sudut lain, untuk tingkat pendidikan dasar dan menengah, ada perbedaan kebijakan dalam pendidikan agama. Ada yang memisahkan pendidikan putera dan puteri, tapi ada juga yang menggabungkan keduanya. Barangkali antara lain dipengaruhi oleh sistem pendidikan di Timur Tengah yang memisahkan pendidikan putera dan puteri, sejumlah pesantren di Indonesia juga melakukan hal yang sama. Mungkin alasannya adalah agar pergaulan putera-puteri bisa dikontrol.Namun ada juga beberapa pesantren yang tidak keberatan dengan pendidikan bersama (koeduaksi) antara dua jenis kelamin itu.Alasannya, pola bercampur itu lebih alamiah.Selain itu, sekolah adalah tempat yang "cukup aman" untuk menjaga pergaulan anak.

Jika demikian keadaan pendidikan perempuan dalam bidang agama, maka pendidikan perempuan dalam bidang ilmu-ilmu lainnya secara umum relatif lebih progresif.Memang, sebagaimana telah disinggung, jika kita perhatikan surat-surat Kartini yang ditulisnya di 
akhir abad ke-19 dan awal abad ke-20, pendidikan perempuan di negeri ini waktu itu masih ketinggalan.Tetapi dia juga menunjukkan bahwa minat masyarakat untuk mengirim anak gadisnya ke sekolah-sekolah umum yang dibuka pemerintah kolonial cukup tinggi.Pada masa kemerdekaan, pendidikan umum terus berkembang pesat, dan boleh dikata hampir tidak ada pembedaan peluang untuk perempuan dan laki-laki.

Di sisi lain, tidak dapat disangkal pula, meskipun peluang pendidikan bagi perempuan terbuka lebar, budaya sebagian masyarakat kita masih ada yang cenderung mengutamakan anak laki-laki untuk disekolahkan lebih tinggi. Meskipun budaya seperti ini tampaknya perlahan-lahan sudah memudar. Selain itu, sebagaimana di banyak tempat, meskipun ada kebebasan memilih jenis pendidikan, kaum perempuan cenderung memilih jenis pendidikan tertentu seperti pendidikan guru, perawat, kedokteran, bidan, ekonomi, sekretaris, manajemen bisnis, jurnalistik dan lain-lain yang dianggap sesuai dengan perempuan. Walaupun ada juga sebagian kecil perempuan yang tertarik untuk jadi tentara, polisi, sopir truk, ahli teknik mesin dan pekerjaan-pekerjaan lain yang umumnya dianggap identik dengan laki-laki.Yang penting di sini adalah bahwa perempuan memiliki kebebasan memilih jenis pendidikan

dan profesi yang ingin digelutinya.

Mengapa

perempuan

pendidikan penting?Karena perempuan, sebagaimana laki-laki, adalah manusia yang berhak mendapatkan pendidikan. Melalui pendidikan, ia akan dapat mengembangkan segenap potensi diri agar ia dapat meraih hidup yang lebih baik. Apalagi, dialah orang yang sejak dini mendidik anak-anak yang lahir dari rahimnya.Sudah umum diketahui di kalangan ilmuwan bahwa pengaruh pikiran dan emosi ibu sangat besar terhadap karakter anak yang dikandungnya.Ini berarti pendidikan ibu sudah terjadi sejak anak itu di dalam kandungan.Jika seorang ibu tidak pernah mendapatkan pendidikan, bagaimana mungkin kita mengharapkannya dapat mendidik anak-anak dengan baik?

Mungkin itulah sebabnya mengapa kedudukan perempuan sebagai ibu sangat dihormati dalam tradisi Islam.Sebuah Hadis yang populer menyebutkan bahwa surga itu terletak di telapak kaki ibu. Dalam Hadis lain diriwayatkan bahwa seorang sahabat bertanya pada Nabi SAW, kepada siapakah dia harus berbakti. Nabi menyebut 'Ibumu' sebanyak tiga kali, baru kemudian beliau menyebut 'Bapakmu'. Sedangkan ayat-ayat Alqur'an sepertinya cenderung menyebut kedua orangtua secara bersamaan, meskipun ada disebutkan 
secara khusus mengenai jasa ibu yang besar pada anak karena dia bersusah payah ketika hamil dan menyusui selama dua tahun (QS Luqman: 14).

Selain itu, ada baiknya kita kembali merenungkan penafsiran simbolik filosofis mengenai sisi maskulin dan feminin dalam diri manusia di atas.Dalam perspektif ini, kelelakian dan keperempuanan dianggap sebagai sifat-sifat tertentu yang ada pada diri manusia apapun jenis kelaminnya.Sifat-sifat tersebut harus dibina dan diletakkan pada posisinya yang tepat.Sifat-sifat maskulin seperti mengontrol, menguasai dan memarahi harus seimbang dengan sifatsifat feminin seperti menyayangi, melindungi dan mengasuh. Tanpa keseimbangan ini, pendidikan akan gagal melahirkan manusia yang berkarakter mulia. Pendidikan bebas, yang membiarkan anak memilih sendiri tanpa bimbingan, saya kira bukanlah pendidikan yang benar.

Menarik bahwa dalam tradisi tasawuf dan falsafah Islam, ruh itu adalah maskulin dan jiwa (al-nafs) itu feminin.Maka ruh yang suci hanya boleh tunduk pada atasannya, yaitu Tuhan. Jika ruh manusia meninggalkan Tuhan dan tunduk pada jiwa, maka dia akan menjadi manusia pengabdi hawa nafsu yang rendah, sehingga menjatuhkan harkat dirinya ke tempat yang paling hina, bahkan lebih hina dari binatang. Maka pendidikan adalah usaha menjadikan ruh sebagai pengendali jiwa, sehingga seseorang akan menjadi manusia yang berakhlak mulia.

\section{KESIMPULAN}

Dari paparan singkat di atas dapatlah kiranya disimpulkan bahwa persoalan Islam dan perempuan menuntut suatu perhatian serius, karena terkait dengan berbagai penafsiran teksteks agama yang otoritatif dan konteks sosial budaya yang melatarbelakanginya. Baik penafsiran yang cenderung konservatif, progresif ataupun filosofissimbolik, semuanya adalah ikhtiar yang patut diapresiasi sebagai upaya kaum Muslim untuk tetap setia kepada agamanya di satu sisi, dan tidak tercerabut dari konteks sosial budaya kehidupannya di sisi lain.

Masalah pendidikan dan perempuan tentu tidak bisa terlepas dari berbagai penafsiran terhadap teks-teks otoritatif keagamaan tersebut.Kaum Muslim umumnya sependapat bahwa menuntut ilmu wajib bagi perempuan, sebagaimana bagi laki-laki.Tetapi kenyataannya, di abad pertengahan yang sering dianggap sebagai masa keemasan Islam, masih jarang kita temukan ilmuwan Muslimah, atau ahli fiqh dan filsafat perempuan. Yang kita temukan hanyalah tokoh-tokoh sufi perempuan, atau para politisi (ratu). Namun, kalau melihat perkembangan di Indonesia, perempuan umumnya 
sejak abad ke-19, sudah banyak yang mempelajari agama bahkan ada yang menulis buku agama.Pendidikan umum kurang diakses oleh perempuan terutama karena tekanan budaya, seperti budaya aristokrat dalam kasus Kartini, ketimbang alasan-alasan keagamaan.Karena itu, dalam hal pendidikan, perempuan Indonesia tampaknya tidak terlalu ketinggalan dari laki-laki, lebih-lebih di abad ke-21 ini.

Mengingat perempuan adalah ibu bagi anak-anak kita, maka pendidikan perempuan tidak hanya sekadar perlu, tetapi sangat penting mendapat perhatian. Pendidikan, bagaimanapun, bermula dari keluarga, dan di situ peran perempuan sebagai ibu sangatlah signifikan. Selain itu, pandangan kaum sufi dan filosof tentang hubungan komplementer antara sifat-sifat maskulin dan feminin dalam diri manusia, patut kiranya menjadi pegangan bagi para pendidik. Pendidikan harus seimbang antara kasih sayang dan ketegasan, antara maaf dan penegakan disiplin.

\section{Endnotes}

1 Untuk pandangan kaum cendekiawan Indonesia dengan spektrum yang beragam, lihat antara lain artikel-artikel dalam Lies M. Marcoes-Natsir dan Johan Hendrik Meuleman (ed.), Wanita Islam Indonesia dalam Kajian Tekstual dan Kontekstual (Jakarta: INIS, 1993).

2 Elizabeth Pisani, Indonesia Etc. Exploring the Improbable Nation (Jakarta: Lontar, 2014), 23.
3 Misalnya, untuk pandangan yang 'ortodoks' dan cukup populer lihat Ibrahim Muhammad al-Jamal, Fiqih Wanita Terj. Anshori Umar Sitanggal (Semarang: CV Asy-Syifa, 1986). Untuk pandangan ulama Indonesia yang lebih progresif, lihat Masdar F. Mas'udi, Islam dan Hak-Hak Reproduksi Perempuan (Bandung: Mizan, 1997); M. Quraish Shihab, Perempuan (Jakarta: Lentera Hati, 2005).

4 Masalah ini pernah dilontarkan oleh Menteri Agama, Munawir Syadzali, hingga memicu perdebatan serius di Indonesia pada akhir 1980-an, yang melibatkan para ulama dan cendekiawan terkemuka. Lihat Iqbal Abdurrauf Saimima (ed.), Polemik Reaktualisasi Ajaran Islam (Jakarta: Pustaka Panjimas, 1988).

5 Lihat Mujiburrahman, "Problematika Hubungan Islam dan Budaya" dalam Wajidi, Akulturasi Budaya Banjar di Banua Halat (Yogyakarta: Pustaka Books Publisher, 2011), xi-xxiii.

6 Sarjana yang paling awal mengemukakan pandangan ini, terutama yang secara eksplisit mengaitkannya dengan ajaran Taoisme, Yin-Yang, tampaknya adalah Toshihiku Izutsu, Sufism and Taoism: A Comparative Study of Key Philosophical Concepts (Berkeley: University of California Press, 1984). Sedangkan studi yang lebih luas dan detil adalah Sachiko Murata, The Tao of Islam: Kitab Rujukan tentang Relasi Gender dalam Kosmologi dan Teologi Islam Terj. Rahmani Astuti dan MS Nasrullah (Bandung: Mizan, 1996).

7 Mujiburrahman, "Bukan Cinderella" Banjarmasin Post, 22 April 2013.

8 Martin van Bruinessen, Kitab Kuning, Pesantren dan Tarekat, edisi revisi (Yogyakarta: Gading, 2012), 211-212.

9 Abdurrahman Wahid, "Dilema Budaya Wanita Islam Indonesia Masa Kini" dalam Marcoes-Natsir dan Meuleman (ed.), Wanita Islam Indonesia..., 229-231.

\section{DAFTAR PUSTAKA}

Abdurrahman Wahid, "Dilema Budaya Wanita Islam Indonesia Masa Kini" dalam Marcoes-Natsir dan Meuleman (ed.), Wanita Islam Indonesia..., 229-231. 
Elizabeth Pisani, Indonesia Etc. Exploring the Improbable Nation (Jakarta: Lontar, 2014), 2-3.

Fromm, Erich. 1962. The Art of Loving. New York: Harper \& Row.

Ibrahim Muhammad al-Jamal, FiqihWanita Terj. Anshori Umar Sitanggal Semarang: CV Asy-Syifa, 1986.

Iqbal Abdurrauf Saimima (ed.), Polemik Reaktualisasi Ajaran Islam Jakarta: Pustaka Panjimas, 1988.

Lies M. Marcoes-Natsir dan Johan Hendrik Meuleman (ed.), Wanita Islam Indonesia dalam Kajian Tekstual dan Kontekstual (Jakarta: INIS, 1993).

Maimunah, Siti. 2013. 'Kita dan WTO'.

Kompas, 3 Desember.

Martin van Bruinessen, Kitab Kuning, Pesantren dan Tarekat, edisi revisi Yogyakarta:Gading, 2012, 211-212.

Masdar F. Mas'udi, Islam dan Hak-Hak Reproduksi Perempuan (Bandung: Mizan, 1997); M. Quraish Shihab, Perempuan (Jakarta: Lentera Hati, 2005).

Mirhan.2012. K.H. Zaini Abdul Ghani di Martapura Kalimantan Selatan
(1942-2005). Banjarmasin: Antasari Press.

Muhajir, Ahmad. 2009. “Tuan Guru and Politics in South Kalimantan: Islam in the 2005 Gubernatorial Elections." MA Thesis. Faculty of Asian Studies, ANU. Tidak Diterbitkan.

Mujiburrahman. 2006. Feeling Threatened: Muslim-Christian Relations in Indonesia's New Order. Amsterdam: Amsterdam University Press.

Mujiburrahman, "Bukan Cinderella" Banjarmasin Post, 22 April 2013.

Mujiburrahman. 2013. Bercermin ke Barat: Pendidikan Islam Antara Ajaran dan Kenyataan. Banjarmasin: Jendela.

Mujiburrahman,"Problematika Hubungan Islam dan Budaya" dalam Wajidi, Akulturasi Budaya Banjar di Banua Halat (Yogyakarta: Pustaka Books Publisher, 2011), xi-xxiii.

Pisani, Elizabeth. 2013. 'A nation of Dunces?' Inside Indonesia. October-December.

Sachiko Murata, The Tao of Islam: Kitab Rujukan tentang Relasi Gender dalam Kosmologi dan Teologi Islam Terj. Rahmani Astuti dan MS 
Nasrullah (Bandung: Mizan, 1996).

Schumacher, E.F. 1985. 'Pandangan Ekonomi Budha' dalam Imam Ahmad ed. Agama dan Tantangan Zaman. Jakarta: LP3ES.

Sukarni. 2011. Fikih Lingkungan Hidup. Banjarmasin: Antasari Press.

Suryadinata, Leo. Arifin, Evi Nurvidya dan Ananta, Aris. 2003.
Indonesia's Population: Ethnicity and Religion in a Changing Political Landscape. Singapore: ISEAS.

Koran: Banjarmasin Post 16 Maret 2013; 3 Desember 2013

Toshihiku Izutsu, Sufism and Taoism: A Comparative Study of Key Philosophical Concepts Berkeley: University of California Press, 1984. 